\title{
Detection of Helminth Ova in Wastewater Using Recombinase Polymerase Amplification Coupled to Lateral Flow Strips
}

\author{
Vivek B. Ravindran ${ }^{1}$ *, Basma Khallaf ${ }^{1}$, Aravind Surapaneni ${ }^{2}$, Nicholas D. Crosbie ${ }^{3}$, \\ Sarvesh K. Soni ${ }^{1}$ and Andrew S. Ball ${ }^{1}$ \\ 1 Centre for Environmental Sustainability and Remediation, School of Science, RMIT University, \\ Bundoora West, VIC 3083, Australia; s3178407@hotmail.com (B.K.); sarvesh.soni@rmit.edu.au (S.K.S.); \\ andy.ball@rmit.edu.au (A.S.B.) \\ 2 South East Water, Frankston, VIC 3199, Australia; aravind.surapaneni@sew.com.au \\ 3 Melbourne Water, Docklands, VIC 3008, Australia; nick.crosbie@melbournewater.com.au \\ * Correspondence: vivek.balakrishnanravindran@rmit.edu.au
}

Received: 3 February 2020; Accepted: 2 March 2020; Published: 3 March 2020

\begin{abstract}
Ascaris lumbricoides is a major soil-transmitted helminth that is highly infective to humans. The ova of $A$. lumbricoides are able to survive wastewater treatment, thus making it an indicator organism for effective water treatment and sanitation. Hence, Ascaris ova must be removed from wastewater matrices for the safe use of recycled water. Current microscopic techniques for identification and enumeration of Ascaris ova are laborious and cumbersome. Polymerase chain reaction (PCR)-based techniques are sensitive and specific, however, major constraints lie in having to transport samples to a centralised laboratory, the requirement for sophisticated instrumentation and skilled personnel. To address this issue, a rapid, highly specific, sensitive, and affordable method for the detection of helminth ova was developed utilising recombinase polymerase amplification (RPA) coupled with lateral flow (LF) strips. In this study, Ascaris suum ova were used to demonstrate the potential use of the RPA-LF assay. The method was faster $(<30 \mathrm{~min})$ with optimal temperature at $37^{\circ} \mathrm{C}$ and greater sensitivity than PCR-based approaches with detection as low as 2 femtograms of DNA. Furthermore, ova from two different helminth genera were able to be detected as a multiplex assay using a single lateral flow strip, which could significantly reduce the time and the cost of helminth identification. The RPA-LF system represents an accurate, rapid, and cost-effective technology that could replace the existing detection methods, which are technically challenged and not ideal for on-site detection in wastewater treatment plants.
\end{abstract}

Keywords: Ascaris; lateral flow; point-of-care; recombinase polymerase amplification; soil-transmitted helminths; wastewater

\section{Introduction}

The reuse of wastewater is widespread across the globe, especially in regions with water scarcity [1,2]. Recycled water can be utilised in irrigation but-if not treated effectively-can pose risk for public health owing to the pathogens present in the recycled water used for irrigation [3-5]. In particular, soil-transmitted helminth ova can survive for several months or years in the environment and are concern where wastewater and sludge reuse are prominent $[6,7]$.

In 1989, the World Health Organization (WHO) focused on the helminth-associated infections that occur due to poor sanitation, poor hygiene, and inadequate water quality [8-10]. Soil-transmitted helminth (STH) infections are of severe concern, affecting nearly one-third of the world's population [9-11]. Ascaris lumbricoides is the major STH, afflicting more than one billion people 
worldwide [12-14] and leading to malnutrition in children, cognitive impairment, and gastrointestinal complications [15-18]. As a result of their environmental hardiness, the WHO recommends parasitic helminth ova as an indicator of sanitary risk and water quality parameters $[19,20]$. WHO recommends an upper limit of one helminth ova per litre for recycled water to be judged suitable for irrigation and public use $[2,21,22]$. Based on such recommendations, the modified Bailenger method was suggested as a universal method for the detection of one helminth ova per 10 litres of recycled water for urban, agricultural, industrial, or environmental use [23,24]. However, the method has drawbacks, such as being time consuming (approximately three days), insensitive, and involves ova recovery, morphological identification, and enumeration of helminth ova [25-27].

Diagnostic tests that are sensitive and specific are critical for monitoring Ascaris species in wastewater and sludge [28-30]. Although polymerase chain reaction (PCR)-based methods provide sufficient sensitivity, specificity, and throughput [1,31,32], their use is limited due to the requirement of a sophisticated device, trained personnel, and storage devices, which are not feasible in most of the endemic countries where poverty is prevalent and resources are limited [33,34]. Consequently, inaccurate diagnosis leads to underestimation of the infection intensity. As such, the elimination goals can only be achieved if more sensitive, rapid, easy to use, and low-cost detection methods are developed.

Recombinase polymerase amplification (RPA) is an isothermal amplification method that has been employed for the detection of various pathogens [35,36]. This approach overcomes the limitations of existing molecular detection methods [37] offering an affordable, sensitive, specific, user-friendly, rapid, robust, readily portable equipment and easily deliverable technique, making this potential technique suitable for onsite diagnosis [38,39].

The RPA reaction is initiated when recombinase binds to the primers. The recombinase-primer complex displaces the target's antisense strand followed by a strand crossover reaction [40]. A single-stranded DNA-binding protein (SSB) attaches to the parental strand, thereby preventing it from interacting with the template strand that has been displaced [35]. DNA polymerase initiates the synthesis of new DNA strands. Since the optimal temperature of the strand synthesis and the amplification process occurs at a constant temperature $\left(37-42{ }^{\circ} \mathrm{C}\right)$, it is considered as isothermal amplification. Recently, RPA was utilised to detect bacteria (Neisseria gonorrhoeae, Salmonella enterica), viruses (Dengue and Yellow Fever virus), and other microbial agents that represent significant public health risks [41-44].

The end-point analysis of RPA can be performed using agarose gel electrophoresis (AGE) [36], real-time quantitative fluorescence [45], and lateral flow strips [46]. AGE takes approximately one hour and exhibits low sensitivity. In contrast, real time quantitative fluorescence is sensitive and rapid but is a tedious process requiring well-equipped facilities and trained personnel. Lateral flow (LF) strips are based on paper oligochromatography and require only 5 to $10 \mathrm{~min}$ to obtain the result [47]. LF strips are cost-effective, yet, with greater accuracy and sensitivity, they offer potential as an important tool for trace target detection [48]. For the visualisation of bands, LF strips are labelled with gold nanoparticles, which are amenable to detection by various methods, provide stability, and are commercially available at a low cost [49]. LF coupled with colloidal gold labelling has been extensively used for qualitative and semi-quantitative detection of target pathogens by visualisation or a simple strip reader [50].

Herein, for the first time, a highly sensitive and rapid recombinase polymerase assay coupled with lateral flow technique is described for the detection of Ascaris ova in wastewater without the requirement of complex equipment, thus representing a potential point-of-care detection assay. The approach focused on the internal transcribed spacer-1 (ITS-1 located between $18 \mathrm{~S}$ and $5.8 \mathrm{~S}$ rRNA genes) region to facilitate detection based on high specificity. Additionally, specificity and sensitivity of this RPA-LF assay were evaluated. 


\section{Materials and Methods}

\subsection{Source of Ascaris Ova}

Ascaris suum (pig roundworm) ova were utilized as surrogate for the human parasite Ascaris lumbricoides owing to $98.1 \%$ genomic similarities and them being morphologically indistinguishable. Additionally, A. lumbricoides causes enormous risk to public health, while A. suum ova can be easily obtained and are much safer, as they rarely infect humans [51]. The A. suum infected pig faecal samples were obtained from an abattoir in Laverton, Australia. The ova of A. suum were recovered using a modified version of the Tulane method [21,52]. Aliquots of pig faecal samples with approximately $5 \mathrm{~g}$ DS (dissolved solid) were rinsed with milliQ water, homogenised for 1 min with a blender, and allowed to settle in 1\% 7X detergent for $30 \mathrm{~min}$ (MP Bio, Australia). The supernatant was aspirated, and the sediment was washed again with $1 \% 7 \mathrm{X}$ to solubilize the organic matter and aid the release of ova that remained adhered to larger particles. After settling, the sediment was poured onto stainless steel sieves of $850 \mu \mathrm{M}$ and $300 \mu \mathrm{M}$ pore sizes (Prospector Earth Sciences, Australia) to remove the larger particles. The filtrate with $A$. suum ova settled further with the addition of $7 X^{\circledR}$ for 30 min, and the sediment was mixed and aliquoted in $50 \mathrm{~mL}$ falcon tubes, which were centrifuged at $800 \mathrm{~g}$, and the supernatant removed.

Ova separation was achieved using flotation with magnesium sulfate (1.20 specific gravity) in each tube. After centrifugation at $800 \mathrm{~g}$ for $3 \mathrm{~min}$, the supernatant was poured on to a $38 \mu \mathrm{M}$ sieve and rinsed with water into a $100 \mathrm{~mL}$ beaker and later transferred into $15 \mathrm{~mL}$ tubes and centrifuged as mentioned above. The ova were enumerated using an optical microscope (x200 magnification) with Universal 4 chamber worm egg counting slides (J. A. Whitlock \& Co, Melbourne, Australia). It was then aliquoted (1000 \pm 20 ova) into $1 \mathrm{~mL}$ volume $(1 \%$ phosphate buffered saline) in $2 \mathrm{~mL}$ Eppendorf tubes and stored at $4{ }^{\circ} \mathrm{C}$ for molecular analysis.

\subsection{DNA Extraction}

The recovered Ascaris ova $(1000 \pm 20)$ were concentrated in $1 \%$ phosphate buffered saline (PBS) to a final volume of $200 \mu \mathrm{L}$. Quick-DNA Fecal/Soil Microbe Miniprep Kit (Zymo Research, Chatswood, Australia) and FastPrep-24 classic instrument (MP Biomedicals, Irvine, USA) were used for DNA isolation from ova. The extracted DNA concentration was measured with NanoDrop spectrophotometer.

\subsection{Design and Screening of RPA Primers}

For the singleplex RPA assay, the ITS ribosomal DNA regions of Ascaris suum (Accession number AB571302) was targeted for amplification. For the multiplex RPA assay, the ITS regions of $A$. suum (Accession number AB571302) and T. suis (Accession number AM993008) were the desired targets. The nucleotide sequences were obtained from Genbank (NCBI). The forward and the reverse RPA primers for each helminth ova were designed using Primer3 plus (Table 1). RPA primers were designed as per the guidelines of TwistDx ${ }^{\mathrm{TM}}$ guidelines (TwistDx, Cambridge, UK). The primers were synthesised to produce smaller amplicon size $(<300 \mathrm{bp})$ to increase the rate of amplification. Between the primers, a gap of at least $52 \mathrm{bp}$ was maintained for probe design for use in lateral flow detection.

The screening of primers was performed with a TwistAmp ${ }^{\mathrm{TM}}$ Basic kit to select the best primer pairs that yielded smaller amplicons. The RPA assay was conducted in a pre-PCR chamber to minimise contamination. For primer screening, 2 ng of A. suum genomic DNA was used as template.

Reactions were performed according to the TwistDx ${ }^{\mathrm{TM}}$ Basic RPA protocol, where each reaction contained $29.5 \mu \mathrm{L}$ rehydration buffer, $2.4 \mu \mathrm{L}$ of both forward and reverse primer (10 pmol), $12.2 \mu \mathrm{L}$ $\mathrm{dH}_{2} \mathrm{O}$, and $1 \mu \mathrm{L}$ genomic DNA. The RPA pellets in the kit were transferred into $0.2 \mathrm{~mL}$ PCR tubes for easy handling. The reaction mix and $2.5 \mu \mathrm{L}$ magnesium acetate were added to the lid of each reaction tube, making a final reaction volume of $50 \mu \mathrm{L}$. The tubes were placed into the thermocycler, and the temperature was set to $37^{\circ} \mathrm{C}$ for $20 \mathrm{~min}$. Since this assay can be a potential POC detection assay, the reaction tubes were also placed in the hands (body temperature) instead of the thermocycler. 
Purification of the amplicons was performed using QIAquick PCR purification kit (Qiagen, Germany) and ran on $2 \%$ agarose gel. Negative controls (no template) were kept for every reaction set. Primer pairs with positive amplification and smaller size amplicons were selected to facilitate rapid amplification

Table 1. Oligonucleotide primers used for initial screening.

\begin{tabular}{|c|c|c|c|}
\hline Assay & Primer & Helminth & Sequence $\left(5^{\prime}-3^{\prime}\right)$ \\
\hline \multirow[t]{6}{*}{$\begin{array}{c}\text { Recombinase } \\
\text { polymerase amplification } \\
\text { (RPA) primer screening }\end{array}$} & Asc718F & $\begin{array}{l}\text { A. suum/A. } \\
\text { lumbricoides }\end{array}$ & CTAATCTATGATTCAATATCTCGTTGTAATTT \\
\hline & Asc881R & & AАATTTTTCATATACATCATTATTGTCACG \\
\hline & Asc709F & & CTTATTTAGCTAATCTATGATTCAATATCTCG \\
\hline & TS596F & T. suis & GTTATTAACGACCAATGCAGATAAGC \\
\hline & TS764R & & GTTCAAAGTATTCAAGTTCAGTGTGTC \\
\hline & TS510F & & CATGCTATGTCGGTGAGGTTTAAAGAA \\
\hline
\end{tabular}

\subsection{Optimisation of Lateral Flow RPA Probe}

The probes targeting the ITS-DNA regions were designed for RPA-LF using the guidelines of TwistDx ${ }^{\mathrm{TM}}$, with size ranging from 46 to 52 nucleotides, incorporating a 6-carboxy-fluorescein (FAM) label at the 5' end. A tetrahydrofuran (THF) residue was added to the probe sequence, and a C3 spacer was incorporated at the $3^{\prime}$ end to prevent extension of any probe that remained unhybridised. One of the primers, in this case, the reverse primer, was added with biotin to the $5^{\prime}$ end (Table 2).

Table 2. Oligonucleotide primers and probe specific for A. suum and T. suis.

\begin{tabular}{ccc}
\hline Assay & Primer/Probe & Sequence $\mathbf{( 5}^{\prime} \mathbf{-} \mathbf{3}^{\prime} \mathbf{)}$ \\
\hline RPA-lateral flow $(\mathrm{LF})$ & Asc718F & CTAATCTATGATTCAATATCTCGTTGTAATTT \\
& Asc881RB & Biotin-AAATTTTTCATATACATCATTATTGTCACG \\
& Asc767P & FAM-ATGAGCGAGAGAGAATATATACATCAAAACG \\
& -Tetrahydrofuran-TCTTAAAAGACGATT-C3 spacer \\
& TS596F & GTTATTAACGACCAATGCAGATAAGC \\
& TS764RD & Digoxigenine-GTTCAAAGTATTCAAGTTCAGTGTGTC \\
& TS661P & FAM-GTGCAGGAACTCTTGAAACATGATGACATT \\
& -tetrahydrofuran-CGAACGGCGGATCACTT-C3 spacer \\
\hline
\end{tabular}

ITS RPA-LF assays were conducted using TwistDx ${ }^{\mathrm{TM}}$ Nfo kit. Each reaction consisted of $2 \mathrm{ng}$ A. suum genomic DNA, $29.5 \mu \mathrm{L}$ rehydration buffer, $2.1 \mu \mathrm{L}$ forward primer, $2.1 \mu \mathrm{L}$ biotin labelled reverse

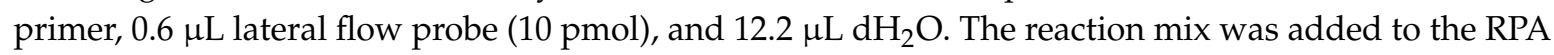
pellets in the kit, and $2.5 \mu \mathrm{L}$ magnesium acetate was transferred to the lids prior to the reaction tube being placed in the thermocycler at $37^{\circ} \mathrm{C}$ for $20 \mathrm{~min}$. Nuclease free water was used as the negative control for the assay.

\subsection{ITS RPA-LF Amplicon Detection}

The end-point analysis of the amplicons was performed using the Milenia HybriDetect 2T lateral flow strips (Milenia Biotec $\mathrm{GmbH}$, Germany). The dipstick is designed for qualitative or quantitative rapid test systems to detect two different analytes. The assay is based on a "sandwich" format with the desired target, where the probe conjugates with anti-FAM antibodies present on the sample pad and captured at the test line by anti-biotin/anti-digoxigenine antibodies, thereby forming a complex with colloidal gold to produce a coloured signal. A coloured band on the control line prevents false negatives.

To avoid contamination, post-amplification processing for RPA-LF was carried out in different rooms of the laboratory. The amplification product $(2 \mu \mathrm{L})$ was added to $98 \mu \mathrm{L}$ HybriDetect buffer. The LF strip was vertically placed into the tube, and the results were read within 3 min. 


\subsection{Reaction Time and Amplification Temperature}

The optimal amplification time for $A$. suum primers was selected by RPA amplification at $37^{\circ} \mathrm{C}$ for 5, 10, 20, 25, 30, and 40 min using $2 \mathrm{ng}$ A. suum DNA, and for the end-point analysis, the lateral flow dipsticks were placed vertically on the tubes for less than $3 \mathrm{~min}$ at room temperature.

Similarly, the evaluation of the optimal temperature for amplification was performed at different reaction temperatures of $20,25,37,40$, and $45{ }^{\circ} \mathrm{C}$ for $20 \mathrm{~min}$. A thermocycler set at the desired temperature was used for this assay. The tubes were manually mixed in the initial 5 min to avoid localised depletion of reagents.

\subsection{Detection Limit and Specificity}

For the lower limit of detection (LLOD), serial dilutions of $A$. suum were prepared using $20 \mathrm{ng} / \mu \mathrm{L}$ DNA with reverse osmosis water to give concentrations of $2 \mathrm{ng} / \mu \mathrm{L}, 200 \mathrm{pg} / \mu \mathrm{L}, 20 \mathrm{pg} / \mu \mathrm{L}, 2 \mathrm{pg} / \mu \mathrm{L}$, $200 \mathrm{fg} / \mu \mathrm{L}, 20 \mathrm{fg} / \mu \mathrm{L}$ and $2 \mathrm{fg} / \mu \mathrm{L}$ of DNA. All reactions were run in the thermocycler at $37^{\circ} \mathrm{C}$ for $20 \mathrm{~min}$.

For determining the specificity of the RPA primers designed for A. suum, organisms such as Trichuris suis (whipworm), Haemonchus contortus (sheep hookworms), and A. lumbricoides were utilised. Faecal samples were collected from pigs that were infected with $T$. suis. The ova were recovered using Tulane method with minor modifications $(21,52)$ and were also used for further experiments. Genomic DNA of A. lumbricoides and H contortus were obtained from the Faculty of Veterinary and Agricultural Sciences, The University of Melbourne. Since DNA of human hookworms Ancylostoma duodenale and Necator americanus were not readily available, NCBI BLAST was performed to evaluate whether the primers could result in cross reactivity to these organisms.

\subsection{Multiplex RPA-LF to Detect Two Different Helminth Ova Genera in Wastewater}

A multiplex RPA-LF was performed to detect two different helminth genera, A. suum and T. suis, in a single lateral flow strip using wastewater from Lang Lang wastewater treatment plant of South East Water, Victoria. Wastewater $(200 \mu \mathrm{L})$ was seeded with $200( \pm 10)$ A. suum and T. suis ova each, and DNA was extracted using Isolate II Genomic Spin Column kits (Bioline, USA). The primers and the probe for T. suis were designed as per the manufacturer's protocol (TwistDx ${ }^{\mathrm{TM}}$, Cambridge, UK) and utilised for this assay. The 3' end of Asc881RB was labelled with biotin, while the 3' end of TS764RD was labelled with digoxigenine. To detect the specificity of the primers, DNA of both $A$. suum and T. suis ( $2 \mathrm{ng}$ ) were amplified using RPA at $37^{\circ} \mathrm{C}$ for $20 \mathrm{~min}$ and observed for coloured test bands using lateral flow dipsticks.

\section{Results}

\subsection{Optimisation of A. Suum Primers (Asc718F/Asc881R)}

The ITS primer combinations successfully amplified $2 \mathrm{ng}$ of $A$. suum DNA. The primers also amplified $A$. lumbricoides DNA. This could have been due to STH's morphological and genetic similarities with A. suum. Agarose gel electrophoresis indicated that the target DNA amplicon lengths were as expected for each set of primers (Figure 1). The primers (Asc718F/Asc881R) with the best band and a shorter amplicon (164 bp) were chosen for further assays, as shorter amplicons generate fewer primer artefacts and thereby provide high sensitivity.

\subsection{Evaluation of Reaction Time and Amplification Temperature}

The RPA assay was performed at $37{ }^{\circ} \mathrm{C}$ for $5-40 \mathrm{~min}$, and the LF assay was performed at approximately $25^{\circ} \mathrm{C}$ (room temperature); the results were analysed within $3 \mathrm{~min}$. The colour observed on the test line was faint at the amplification time of $5 \mathrm{~min}$; however, the colour intensity at the test line increased at $10 \mathrm{~min}$ amplification time with a strong positive signal (Figure 2A). For rapid and greater 
sensitivity, a 20 min RPA assay is recommended, though an amplification of 5 min was sufficient to detect the pathogen. The time taken for RPA-LF was 30 min or less.

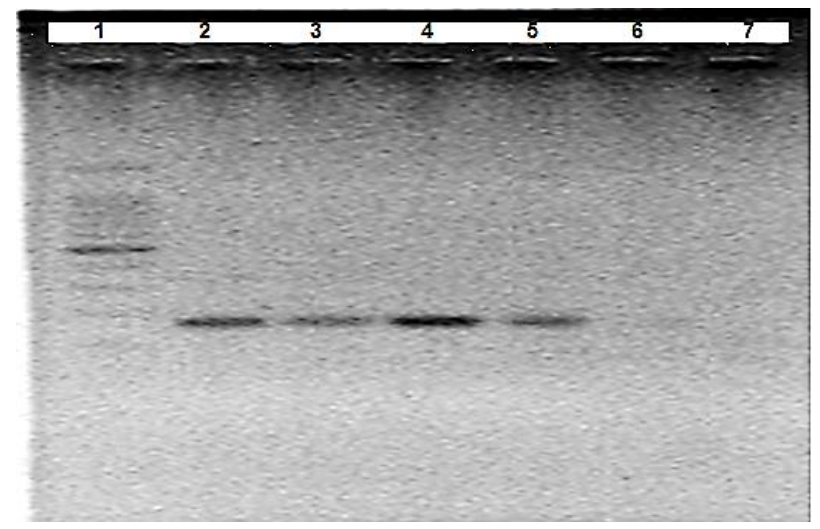

Figure 1. Validation of Asc718F/Asc881R primer pair for target Ascaris DNA: 1) $100 \mathrm{bp}$ Ladder, 2) Ascaris suum, 3) A. lumbricoides, 4) A. suum (1:10 genomic DNA dilution), 5) A.lumbricoides (1:10 genomic DNA dilution), 6) Trichuris suis, 7) no template (negative control).

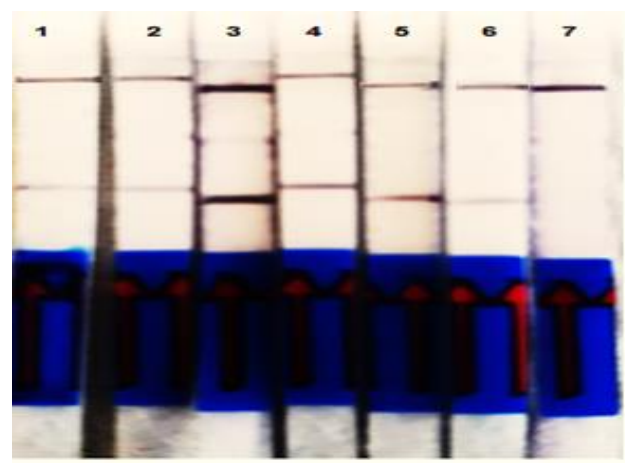

A

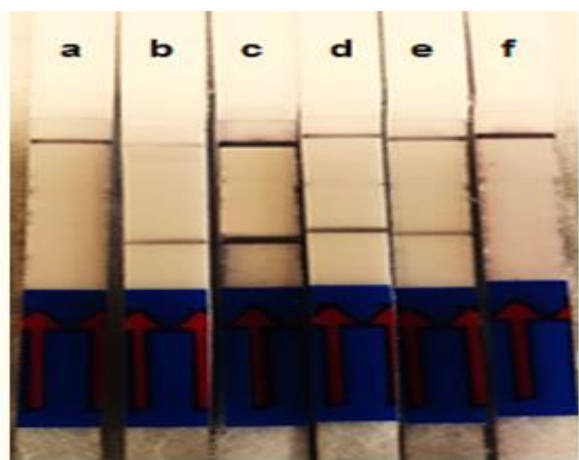

B

Figure 2. (A) Determination of reaction time for RPA-LF assay using primers for A. suum: 1) $5 \mathrm{~min}$, 2) $10 \mathrm{~min}$, 3) $20 \mathrm{~min}$, 4) $25 \mathrm{~min}, 5) 30 \mathrm{~min}, 6) 40 \mathrm{~min}$, and 7) control (no template). (B) Determination of amplification temperature for RPA-LF assay: a) $20{ }^{\circ} \mathrm{C}$, b) $25^{\circ} \mathrm{C}$, c) $37^{\circ} \mathrm{C}$, d) $40^{\circ} \mathrm{C}$, e) $45^{\circ} \mathrm{C}$, f) no template control.

The results for the optimal amplification temperature depicted the performance of the assay at temperatures ranging from $25-45^{\circ} \mathrm{C}$ (Figure $2 \mathrm{~B}$ ). The colour intensity in the test line changed with temperature, suggesting the importance of temperature for efficient amplification. A clear band with high visibility appeared at $37^{\circ} \mathrm{C}$, and it was chosen at the optimal temperature for amplification of A. suum DNA.

\subsection{Evaluation of Detection Limit and Specificity}

The LLOD of the RPA-LF assay was analysed using $2 \mathrm{ng}$ of $A$. lumbricoides DNA and dilutions of A suum DNA as low as $2 \mathrm{fg}$. The negative control consisted of nuclease free water. The presence of a band in both the control and the test bands indicated a positive result, while a coloured band at the control line alone indicated a negative result. As shown, two purple bands on the lateral flow strips were observed post-amplification from $2 \mathrm{ng}$ to $2 \mathrm{fg}$ but not the negative control (Figure 3). The results showed that the RPA-LF assay detected as low as $2 \mathrm{fg}$ genomic DNA and has the potential to detect even one helminth ovum. 


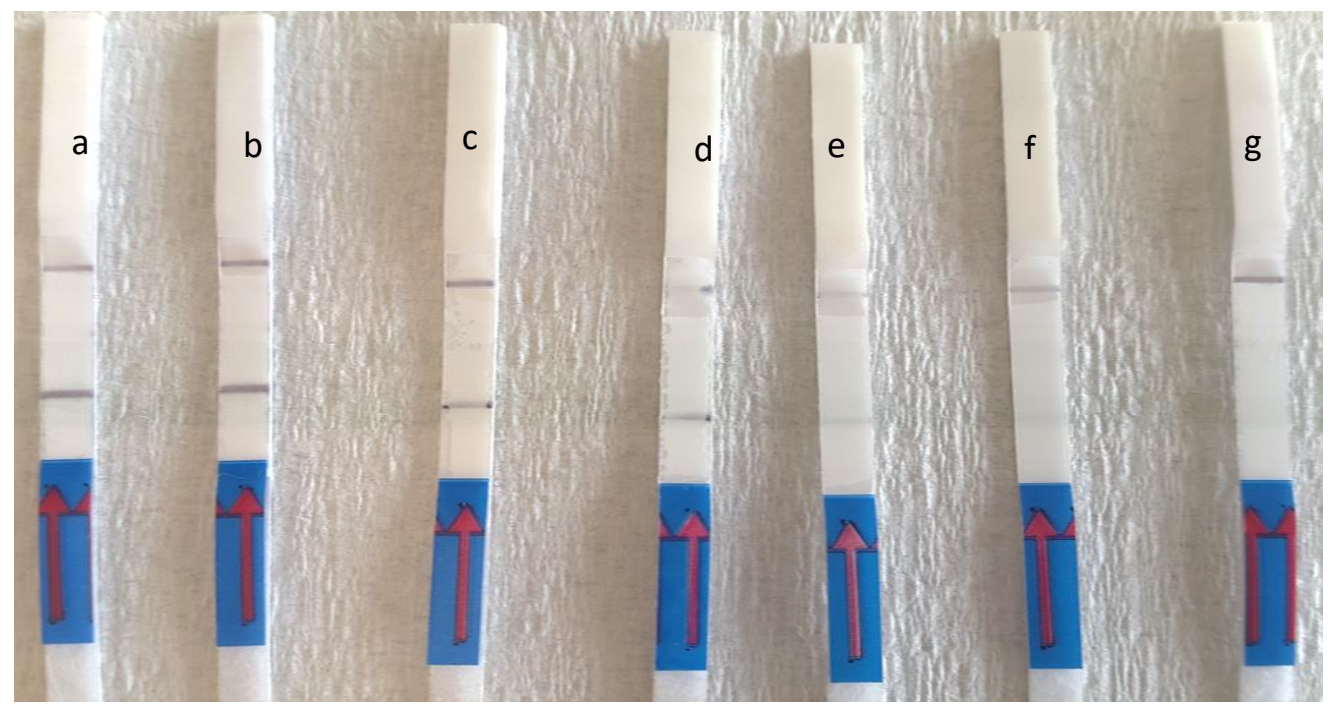

Figure 3. Sensitivity of RPA-LF primers for Ascaris: a) A. lumbricoides 2 nanogram (ng) DNA, (b-g) $A$. suum, b) 2 ng, c) 200 picogram (pg), d) 2 picogram, e) 20 femtogram (fg), f) 2 fg, g) control.

Similarly, the analytical specificity of the assay was tested using 2 ng genomic DNA from $A$. suum, A. lumbricoides, T. suis, and H. contortus. The negative control consisted of nuclease free water. A coloured test band was visualised on the LF strips of A. suum and A. lumbricoides DNA, while other helminth ova genera were found to be negative (Figure 4), thus revealing that RPA primers showed high specificity for Ascaris ova.

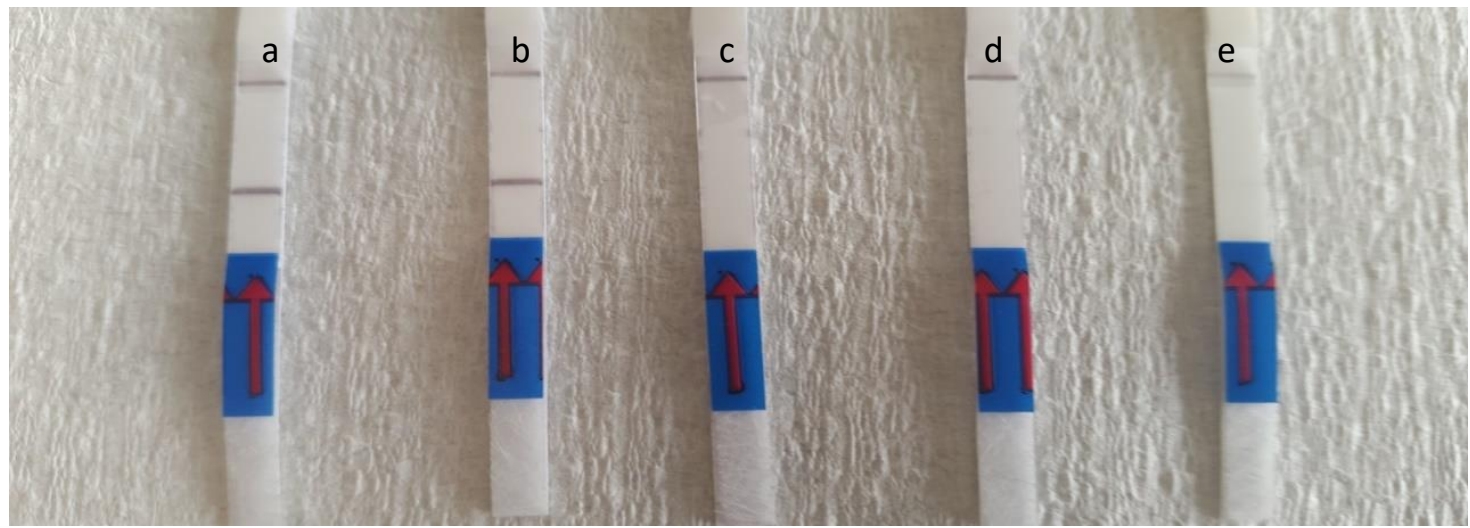

Figure 4. Evaluating the specificity of Ascaris primers using RPA-LF assay: a) Ascaris lumricoides, b) Ascaris suum, c) Trichuris suis, d) Haemonchus contortus, e) control.

\subsection{Multiplex RPA-LF Assay}

The results for multiplex RPA-LF to detect $A$. suum and T. suis in a single strip showed the capability of the primers specific for the target DNA with no cross reactivity. A clear visible test band was observed at the bottom, indicating the detection of A. suum, and the test band below the control band indicates the presence of T. suis. However, the reaction tube containing DNA and primers of both A. suum and T. suis showed three bands, indicating the control band and both the test bands were observed and therefore demonstrating the successful detection of both helminth ova genera (Figure 5). 


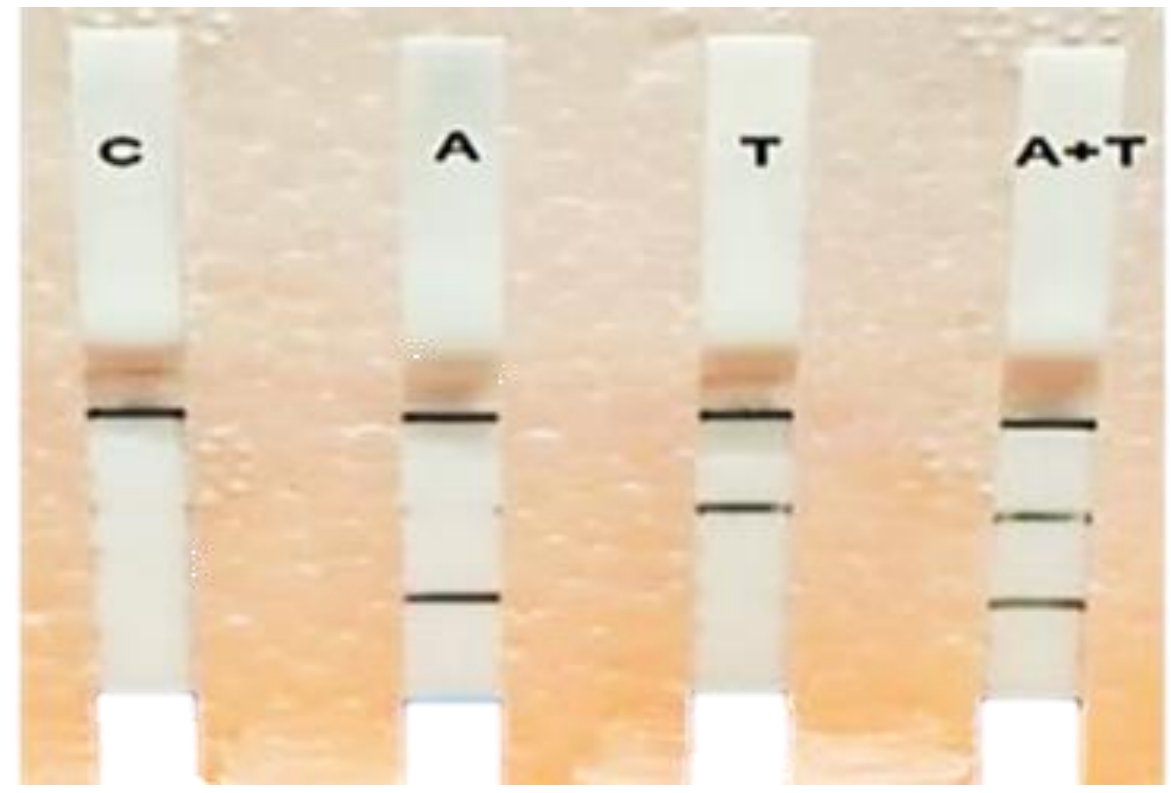

Figure 5. Multiplex RPA-LF: C) control (no template), A) A. suum and T. suis DNA with T) T. suis and A. suum DNA with $\mathrm{A}+\mathrm{T}$ ) both $A$. suum and T. suis DNA and primers.

\section{Discussion}

Diagnostic tests with greater specificity and sensitivity are crucial to successfully detect the presence of Ascaris ova in recycled water prior to release for public use [53]. Such a test will also help to monitor the transmission of ascariasis in endemic and low resource setting areas. Conventional microscopy and culture methods are laborious and cumbersome [6,54]. Despite the fact that PCR based methods are specific and sensitive, they possess limitations such as high cost, slow turnaround times, and difficulty of application in low resource settings [55]. In this study, utilising the TwistDx platform, RPA methods were coupled with a lateral flow (RPA-LF) assay to detect Ascaris species (singleplex RPA) in seeded wastewater. Furthermore, a novel duplex RPA-LF assay was performed to detect ova from two different helminth genera (A. suum and T. suis) in a single LF strip.

Ribosomal ITS DNA of A. suum was utilised in the design of primers and probe, and the best primer pair that produced shorter amplicons was chosen. The assay was repeated at least twice with the primer pairs to avoid false positive/negative results, which can arise owing to the formation of hairpin secondary structure of primer/probe leading to non-specific amplification. The addition of dimethyl sulfoxide (DMSO) prevented false positives. DMSO has the ability to avoid secondary structures, especially in GC rich sequences, and is often used in nucleic acid amplification [56].

The RPA-LF assay detected $2 \mathrm{fg}$ genomic DNA of A. suum, thus exhibiting the assay's potential in detecting even one ovum in large volumes of wastewater samples. Post-amplification contamination with RPA-LF assay can be minimised by carefully opening and closing the reaction tubes, frequently changing the gloves, conducting pre- and post-RPA assays in different chambers or locations, and reducing the reaction time if required.

Furthermore, this RPA-LF assay showed no cross-reaction with other organisms and exhibited high specificity for Ascaris ova. Other advantages were the constant (isothermal) amplification temperature and the shorter reaction time for the assay. Our study indicated that the assay could be successfully conducted at temperatures ranging from 25 to $45^{\circ} \mathrm{C}$, thus it is effective at various temperature ranges without the requirement of any heating device; simply placing the reaction tubes in the hand is sufficient for amplification. Besides, the overall processing time of the RPA-LF assay from amplification to detection by visualisation of purple coloured bands was $30 \mathrm{~min}$ or less, significantly faster than the currently available isothermal amplification methods, such as loop mediated isothermal amplification (LAMP), which requires $64^{\circ} \mathrm{C}$ for $90 \mathrm{~min}$ [29]. Subsequently, the results for the validation of RPA-LF 
to detect Ascaris ova in seeded wastewater showed that turbidity did not have an impact on the sensitivity of this assay, which could be ideal for the onsite detection of helminth ova in wastewater treatment plants.

Finally, the multiplex RPA-LF assay showed that the assay was effective in detecting the ova of A. suum and T. suis in a single LF strip. Multiplex RPA-LF based detection of two different pathogens in a single strip could significantly reduce time, cost, and labour [48,57]. Further optimisation and validation may prove RPA-LF to be a feasible detection test for Ascaris species in wastewater. Moreover, the results denoted that the technique is user-friendly and could be performed by untrained personnel in wastewater treatment plants. No sophisticated devices or training are required, making this approach ideal for endemic and resource limited areas.

\section{Conclusions}

The RPA-LF reported in this study was rapid and highly sensitive in the detection of $A$. suum ova. Additionally, for the first time, the ova of two different helminth genera were able to be detected in a single strip using a multiplex approach. Nevertheless, the effectiveness of RPA-LF for the detection of helminths in wastewater with varying turbidity and from endemic regions must be evaluated prior to being utilised as a routine point-of-care detection test for STHs in wastewater treatment plants. Overall, RPA is an efficient isothermal amplification method that can overcome the limitations encountered by existing molecular diagnostics methods. RPA reactions operate at varying temperature ranges $\left(25-45^{\circ} \mathrm{C}\right)$, confirming the ability of this assay to be efficient over a range of temperatures and settings and thereby enhancing the potential of RPA-LF feasible in resource-limited areas where power supply is a constraint. RPA coupled with LF detection method is very simple and requires no skilled personnel to interpret the results. Furthermore, development of a device-free, simple, and rapid DNA extraction method can be combined with RPA-LF for efficient onsite diagnostic purposes.

Author Contributions: Conceptualization, V.B.R., S.K.S., A.S.B.; resources, S.K.S., A.S.B.; writing-original draft preparation, V.B.R., B.K.; writing-review and editing, V.B.R., S.K.S., A.S.B., A.S., N.D.C.; visualization, V.B.R.; supervision, S.K.S., A.S.B.; project administration, A.S.B. All authors have read and agreed to the published version of the manuscript.

Funding: The research did not receive any specific grant from funding agencies in the public, commercial, or not-for-profit sectors.

Acknowledgments: The authors acknowledge support from the RMIT Postgraduate International Scholarship, RMIT-ECP Opportunity Grant and RMIT Research Translation Seed Funding for the development of this research. We also acknowledge South East Water, Melbourne Water and Rebecca Traub, Faculty of Veterinary and Agricultural Sciences, The University of Melbourne, Australia, for providing samples and necessary inputs for this research. Furthermore, we thank the members of Ball's group, School of Science, RMIT University, Melbourne, Australia, for providing valuable insights.

Conflicts of Interest: The authors declare no conflict of interest.

\section{References}

1. Rocha, M.C.V.D.; Barés, M.E.; Braga, M.C.B. Quantification of viable helminth eggs in samples of sewage sludge. Water Res. 2016, 103, 245-255. [CrossRef]

2. Acosta Soto, L.; Santísima-Trinidad, A.B.; Bornay-Llinares, F.J.; Martín González, M.; Pascual Valero, J.A.; Ros Muñoz, M. Quantitative PCR and Digital PCR for Detection of Ascaris lumbricoides Eggs in Reclaimed Water. Biomed. Res. Int. 2017, 2017, 9. [CrossRef]

3. Gyawali, P.; Sidhu, J.P.; Ahmed, W.; Jagals, P.; Toze, S. Rapid concentration and sensitive detection of hookworm ova from wastewater matrices using a real-time PCR method. Exp. Parasitol. 2015, 159, 5-12. [CrossRef]

4. Gyawali, P. Infectious helminth ova in wastewater and sludge: A review on public health issues and current quantification practices. Water Sci. Technol. A J. Int. Assoc. Water Pollut. Res. 2018, 77, 1048-1061. [CrossRef] 
5. Li, D.; Tong, T.; Zeng, S.; Lin, Y.; Wu, S.; He, M. Quantification of viable bacteria in wastewater treatment plants by using propidium monoazide combined with quantitative PCR (PMA-qPCR). J. Environ. Sci. 2014, 26, 299-306. [CrossRef]

6. Collender, P.A.; Kirby, A.E.; Addiss, D.G.; Freeman, M.C.; Remais, J.V. Methods for Quantification of Soil-Transmitted Helminths in Environmental Media: Current Techniques and Recent Advances. Trends Parasitol. 2015, 31, 625-639. [CrossRef]

7. Amoah, I.D.; Singh, G.; Stenström, T.A.; Reddy, P. Detection and quantification of soil-transmitted helminths in environmental samples: A review of current state-of-the-art and future perspectives. Acta Trop. 2017, 169, 187-201. [CrossRef]

8. Bethony, J.; Brooker, S.; Albonico, M.; Geiger, S.M.; Loukas, A.; Diemert, D.; Hotez, P.J. Soil-transmitted helminth infections: Ascariasis, trichuriasis, and hookworm. Lancet 2006, 367, 1521-1532. [CrossRef]

9. Hotez, P.J.; Brooker, S.; Bethony, J.M.; Bottazzi, M.E.; Loukas, A.; Xiao, S. Hookworm Infection. N. Engl. J. Med. 2004, 351, 799-807. [CrossRef]

10. Hotez, P.J.; Damania, A.; Barua, A.; Stanaway, J. The first "London Declaration": The Commonwealth and its neglected tropical diseases. PLoS Negl. Trop. Dis. 2017, 11, e0005321. [CrossRef]

11. Du, R.Y.; Stanaway, J.D.; Hotez, P.J. Could violent conflict derail the London Declaration on NTDs? PLoS Negl. Trop. Dis. 2018, 12, e0006136. [CrossRef]

12. Karkashan, A.; Khallaf, B.; Morris, J.; Thurbon, N.; Rouch, D.; Smith, S.R.; Deighton, M. Comparison of methodologies for enumerating and detecting the viability of Ascaris eggs in sewage sludge by standard incubation-microscopy, the BacLight Live/Dead viability assay and other vital dyes. Water Res. 2015, 68, 533-544. [CrossRef]

13. Shahsavari, E.; Schmidt, J.; Aburto-Medina, A.; Khallaf, B.; Balakrishnan, V.; Crosbie, N.D.; Surapaneni, A.; Ball, A.S. A modified assay for the enumeration of ascaris eggs in fresh raw sewage. MethodsX 2017, 4, 186-190. [CrossRef]

14. Mascarini-Serra, L. Prevention of Soil-transmitted Helminth Infection. J. Glob. Infect. Dis. 2011, 3, $175-182$. [CrossRef]

15. Salam, N.; Azam, S. Prevalence and distribution of soil-transmitted helminth infections in India. BMC Public Health 2017, 17, 201. [CrossRef]

16. Mara, D.; Sleigh, A. Estimation of Ascaris infection risks in children under 15 from the consumption of wastewater-irrigated carrots. J. Water Health 2010, 8, 35-38. [CrossRef]

17. Schmidlin, T.; Hürlimann, E.; Silué, K.D.; Yapi, R.B.; Houngbedji, C.; Kouadio, B.A.; Acka-Douabélé, C.A.; Kouassi, D.; Ouattara, M.; Zouzou, F.; et al. Effects of hygiene and defecation behavior on helminths and intestinal protozoa infections in Taabo, Côte d'Ivoire. PLoS ONE 2013, 8, e65722. [CrossRef]

18. Strunz, E.C.; Addiss, D.G.; Stocks, M.E.; Ogden, S.; Utzinger, J.; Freeman, M.C. Water, Sanitation, Hygiene, and Soil-Transmitted Helminth Infection: A Systematic Review and Meta-Analysis. PLoS Med. 2014, 11, e1001620. [CrossRef]

19. Manser, N.D.; Wald, I.; Ergas, S.J.; Izurieta, R.; Mihelcic, J.R. Assessing the fate of Ascaris suum ova during mesophilic anaerobic digestion. Environ. Sci. Technol. 2015, 49, 3128-3135. [CrossRef]

20. Cruz, L.M.; Allanson, M.; Kwa, B.; Azizan, A.; Izurieta, R. Morphological Changes of Ascaris spp. Eggs During Their Development Outside the Host. J. Parasitol. 2011, 98, 63-68. [CrossRef]

21. Bowman, D.D.; Little, M.D.; Reimers, R.S. Precision and accuracy of an assay for detecting Ascaris eggs in various biosolid matrices. Water Res. 2003, 37, 2063-2072. [CrossRef]

22. Maya, C.; Ortiz, M.; Jimenez, B. Viability of Ascaris and other helminth genera non larval eggs in different conditions of temperature, lime ( $\mathrm{pH})$ and humidity. Water Sci. Technol. A J. Int. Assoc. Water Pollut. Res. 2010, 62, 2616-2624. [CrossRef] [PubMed]

23. Horiuchi, S.; Uga, S. Modified flotation method, an effective technique for recovering helminth eggs in soil. Parasitol. Int. 2016, 65, 576-579. [CrossRef]

24. Sá, M.F.D.; Gonçalves, R.A.; Marder, C.; Baldissera, M.D.; Oliveira, C.B.D.; Noll, J.C.G.; Silva, F.; Monteiro, S.G. Adapted Bailenger method improves the rate of Ascaris suum eggs recovery from liquid pig manure compost. Ciência Rural 2017, 47, 1-6.

25. O'Connor, N.A.; Surapaneni, A.; Smith, D.; Stevens, D. Occurrence and fate of Ascaris lumbricoides ova in biosolids in Victoria, Australia: A human health risk assessment of biosolids storage periods. Water Sci. Technol. A J. Int. Assoc. Water Pollut. Res. 2017, 76, 1332-1346. [CrossRef] 
26. Stevens, D.P.; Surapaneni, A.; Thodupunuri, R.; O'Connor, N.A.; Smith, D. Helminth log reduction values for recycling water from sewage for the protection of human and stock health. Water Res. 2017, 125, 501-511. [CrossRef]

27. Llewellyn, S.; Inpankaew, T.; Nery, S.V.; Gray, D.J.; Verweij, J.J.; Clements, A.C.; Gomes, S.J.; Traub, R.; McCarthy, J.S. Application of a Multiplex Quantitative PCR to Assess Prevalence and Intensity Of Intestinal Parasite Infections in a Controlled Clinical Trial. PLoS Negl. Trop. Dis. 2016, 10, e0004380. [CrossRef]

28. Wardell, R.; Clements, A.C.; Lal, A.; Summers, D.; Llewellyn, S.; Campbell, S.J.; McCarthy, J.; Gray, D.J.; Nery, S.V. An environmental assessment and risk map of Ascaris lumbricoides and Necator americanus distributions in Manufahi District, Timor-Leste. PLoS Negl. Trop. Dis. 2017, 11, e0005565. [CrossRef]

29. Shiraho, E.A.; Eric, A.L.; Mwangi, I.N.; Maina, G.M.; Kinuthia, J.M.; Mutuku, M.W.; Mugambi, R.M.; Mwandi, J.M.; Mkoji, G.M. Development of a Loop Mediated Isothermal Amplification for Diagnosis of Ascaris lumbricoides in Fecal Samples. J. Parasitol. Res. 2016, 2016, 7376207. [CrossRef]

30. Bastos, V.K.; Cutolo, S.A.; Doria, M.d.C.O.; Razzolini, M.T.P. Detection and quantification of viable Ascaris sp. and other helminth eggs in sewage sludge. Int. J. Environ. Health Res. 2013, 23, 352-362. [CrossRef]

31. Pecson, B.M.; Barrios, J.A.; Johnson, D.R.; Nelson, K.L. A Real-Time PCR Method for Quantifying Viable Ascaris Eggs Using the First Internally Transcribed Spacer Region of Ribosomal DNA. Appl. Environ. Microbiol. 2006, 72, 7864-7872. [CrossRef] [PubMed]

32. Gordon, C.A.; McManus, D.P.; Acosta, L.P.; Olveda, R.M.; Williams, G.M.; Ross, A.G.; Gray, D.J.; Gobert, G.N. Multiplex real-time PCR monitoring of intestinal helminths in humans reveals widespread polyparasitism in Northern Samar, the Philippines. Int. J. Parasitol. 2015, 45, 477-483. [CrossRef] [PubMed]

33. Drain, P.K.; Hyle, E.P.; Noubary, F.; Freedberg, K.A.; Wilson, D.; Bishai, W.R.; Rodriguez, W.; Bassett, I.V. Diagnostic point-of-care tests in resource-limited settings. Lancet Infect. Dis. 2014, 14, 239-249. [CrossRef]

34. Mugambi, R.M.; Agola, E.L.; Mwangi, I.N.; Kinyua, J.; Shiraho, E.A.; Mkoji, G.M. Development and evaluation of a Loop Mediated Isothermal Amplification (LAMP) technique for the detection of hookworm (Necator americanus) infection in fecal samples. Parasit Vectors 2015, 8, 574. [CrossRef]

35. Daher, R.K.; Stewart, G.; Boissinot, M.; Bergeron, M.G. Recombinase Polymerase Amplification for Diagnostic Applications. Clin. Chem. 2016, 62, 947-958. [CrossRef]

36. Lau, H.Y.; Botella, J.R. Advanced DNA-Based Point-of-Care Diagnostic Methods for Plant Diseases Detection. Front. Plant Sci. 2017, 8, 2016. [CrossRef]

37. Li, J.; Macdonald, J.; von Stetten, F. Review: A comprehensive summary of a decade development of the recombinase polymerase amplification. Analyst 2019, 144, 31-67. [CrossRef]

38. Yang, Y.; Qin, X.; Song, Y.; Zhang, W.; Hu, G.; Dou, Y.; Li, Y.; Zhang, Z. Development of real-time and lateral flow strip reverse transcription recombinase polymerase Amplification assays for rapid detection of peste des petits ruminants virus. Virol. J. 2017, 14, 24. [CrossRef]

39. Wang, J.; Liu, L.; Wang, J.; Sun, X.; Yuan, W. Recombinase Polymerase Amplification Assay-A Simple, Fast and Cost-Effective Alternative to Real Time PCR for Specific Detection of Feline Herpesvirus-1. PLoS ONE 2017, 12, e0166903. [CrossRef]

40. James, A.; Macdonald, J. Recombinase polymerase amplification: Emergence as a critical molecular technology for rapid, low-resource diagnostics. Expert Rev. Mol. Diagn. 2015, 15, 1475-1489. [CrossRef]

41. Euler, M.; Wang, Y.; Heidenreich, D.; Patel, P.; Strohmeier, O.; Hakenberg, S.; Niedrig, M.; Hufert, F.T.; Weidmann, M. Development of a Panel of Recombinase Polymerase Amplification Assays for Detection of Biothreat Agents. J. Clin. Microbiol. 2013, 51, 1110. [CrossRef]

42. Escadafal, C.; Faye, O.; Sall, A.A.; Faye, O.; Weidmann, M.; Strohmeier, O.; von Stetten, F.; Drexler, J.; Eberhard, M.; Niedrig, M.; et al. Rapid Molecular Assays for the Detection of Yellow Fever Virus in Low-Resource Settings. PLoS Negl. Trop. Dis. 2014, 8, e2730. [CrossRef]

43. Kersting, S.; Rausch, V.; Bier, F.F.; von Nickisch-Rosenegk, M. Multiplex isothermal solid-phase recombinase polymerase amplification for the specific and fast DNA-based detection of three bacterial pathogens. Mikrochim. Acta 2014, 181, 1715-1723. [CrossRef]

44. Teoh, B.T.; Sam, S.S.; Tan, K.K.; Danlami, M.B.; Shu, M.H.; Johari, J.; Hooi, P.S.; Brooks, D.; Piepenburg, O.; Nentwich, O; et al. Early Detection of Dengue Virus by Use of Reverse Transcription-Recombinase Polymerase Amplification. J. Clin. Microbiol. 2015, 53, 830. [CrossRef] 
45. Zhang, S.; Ravelonandro, M.; Russell, P.; McOwen, N.; Briard, P.; Bohannon, S.; Vrient, A. Rapid diagnostic detection of plum pox virus in Prunus plants by isothermal AmplifyRP((R)) using reverse transcription-recombinase polymerase amplification. J. Virol. Methods 2014, 207, 114-120. [CrossRef]

46. Tu, P.A.; Shiu, J.S.; Lee, S.H.; Pang, V.F.; Wang, D.C.; Wang, P.H. Development of a recombinase polymerase amplification lateral flow dipstick (RPA-LFD) for the field diagnosis of caprine arthritis-encephalitis virus (CAEV) infection. J. Virol. Methods 2017, 243, 98-104. [CrossRef]

47. Soliman, H.; Kumar, G.; El-Matbouli, M. Recombinase polymerase amplification assay combined with a lateral flow dipstick for rapid detection of Tetracapsuloides bryosalmonae, the causative agent of proliferative kidney disease in salmonids. Parasites Vectors 2018, 11, 234. [CrossRef]

48. Tian, A.L.; Elsheikha, H.M.; Zhou, D.H.; Wu, Y.D.; Chen, M.X.; Wang, M.; Chen, D.; Zhang, X.C.; Zhu, X.Q. A novel recombinase polymerase amplification (RPA) assay for the rapid isothermal detection of Neospora caninum in aborted bovine fetuses. Vet. Parasitol. 2018, 258, 24-29. [CrossRef]

49. Sun, K.; Xing, W.; Yu, X.; Fu, W.; Wang, Y.; Zou, M.; Luo, Z.; Xu, D. Recombinase polymerase amplification combined with a lateral flow dipstick for rapid and visual detection of Schistosoma japonicum. Parasit Vectors 2016, 9, 476. [CrossRef]

50. Rohrman, B.; Richards-Kortum, R. Inhibition of recombinase polymerase amplification by background DNA: A lateral flow-based method for enriching target DNA. Anal. Chem. 2015, 87, 1963-1967. [CrossRef]

51. Nejsum, P.; Thamsborg, S.M.; Petersen, H.H.; Kringel, H.; Fredholm, M.; Roepstorff, A. Population dynamics of Ascaris suum in trickle-infected pigs. J. Parasitol. 2009, 95, 1048. [CrossRef]

52. Ravindran, V.B.; Surapaneni, A.; Crosbie, N.D.; Schmidt, J.; Shahsavari, E.; Haleyur, N.; Soni, S.K.; Ball, A.S. A modified approach to recover and enumerate Ascaris ova in wastewater and sludge. PLoS Negl. Trop. Dis. 2018, 13, 1-6. [CrossRef]

53. Steinbaum, L.; Kwong, L.H.; Ercumen, A.; Negash, M.S.; Lovely, A.J.; Njenga, S.M.; Boehm, A.B.; Pickering, A.J.; Nelson, K.L. Detecting and enumerating soil-transmitted helminth eggs in soil: New method development and results from field testing in Kenya and Bangladesh. PLoS Negl. Trop. Dis. 2017, 11, e0005522. [CrossRef]

54. Pilotte, N.; Papaiakovou, M.; Grant, J.R.; Bierwert, L.A.; Llewellyn, S.; McCarthy, J.S.; Williams, S.A. Improved PCR-Based Detection of Soil Transmitted Helminth Infections Using a Next-Generation Sequencing Approach to Assay Design. PLoS Negl. Trop. Dis. 2016, 10, e0004578. [CrossRef]

55. Verweij, J.J.; Stensvold, C.R. Molecular testing for clinical diagnosis and epidemiological investigations of intestinal parasitic infections. Clin. Microbiol. Rev. 2014, 27, 371-418. [CrossRef]

56. Jensen, M.A.; Fukushima, M.; Davis, R.W. DMSO and betaine greatly improve amplification of GC-rich constructs in de novo synthesis. PLoS ONE 2010, 5, e11024. [CrossRef]

57. Pai, N.P.; Vadnais, C.; Denkinger, C.; Engel, N.; Pai, M. Point-of-care testing for infectious diseases: Diversity, complexity, and barriers in low- and middle-income countries. PLoS Med. 2012, 9, e1001306. [CrossRef] 